\title{
Titrimetric and Spectrophotometric Determination of Some Thiadiazole Derivatives by Using Amplification Reactions
}

\author{
Mahmood M. Barbooti ${ }^{*}$, Ridha I. Al-Bayati², Asra A. Hussain ${ }^{2}$ \\ ${ }^{1}$ Department of Applied Science, University of Technology, Baghdad, Iraq \\ ${ }^{2}$ Department of Chemistry, College of Science, Al-Mustansiriya University, Baghdad, Iraq \\ Email: *brbt2m@gmail.com
}

How to cite this paper: Barbooti, M.M., Al-Bayati, R.I. and Hussain, A.A. (2021) Titrimetric and Spectrophotometric Determination of Some Thiadiazole Derivatives by Using Amplification Reactions. American Journal of Analytical Chemistry, 12, 46-58.

https://doi.org/10.4236/ajac.2020.122004

Received: January 23, 2021

Accepted: February 22, 2021

Published: February 25, 2021

Copyright (๑) 2021 by author(s) and Scientific Research Publishing Inc. This work is licensed under the Creative Commons Attribution International License (CC BY 4.0).

http://creativecommons.org/licenses/by/4.0/

(c) (i) Open Access

\begin{abstract}
The principle of using amplification reactions of iodine was employed in this paper to estimate the thiadiazole derivatives on basis of their reactions with iodine I chloroform, removal of the excess iodine and determination of the resulting iodide, after oxidation to iodate. The overall reaction gave an amplification of the iodide that is (12) times larger for the compounds: 2-amino-5mercapto-1,3,4-thiadiazole (I); 2,5-dimercapto-1,3,4-thiadiaole (II) and 2,5diamino-1,3,4-thiadiazole (III) and (36) times for 2,5-dihydrazino-1,3,4thiadiazole (IV) and (6) times for 5-mercapto-2 [(3[5'-nitro-2-'furyl]-methylene)amino]-1,3,4-thiadiazole (V) and 5-mercapto-2[(3[5'-nitro-2-'furyl]-prop2-enylidene)amino]-1,3,4-thiadiazole (VI). By titration, 1-mL of standard thiosulfate solution was found equivalent to $0.108 \mathrm{mg}$ of (I); $0.126 \mathrm{mg}$ of (II), $0.16 \mathrm{mg}$ of (III), $0.041 \mathrm{mg}$ of (IV), $0.40 \mathrm{mg}$ of (V) and $0.435 \mathrm{mg}$ of (VI). Using the spectrophotometric detection for the amplification reaction gave high absorbance values at $605 \mathrm{~nm}$ for the blue starch-iodine complex. Beer's law was obeyed up to $4.0 \mathrm{ppm}$ for compounds (I and II); $6.0 \mathrm{ppm}$ for compounds (III, IV and VI) and $5.0 \mathrm{ppm}$ for compound (V). The mechanism of the reactions was proposed and the analytical parameters were evaluated for both methods. The method was applied for synthetic samples of industrial importance. The recovery was comparable while the sensitivity and detection limits were better for the spectrophotometric detection.
\end{abstract}

\section{Keywords}

Thiadiazoles, Titrimetry, Amplification Reaction, Spectrophotometric Determination 


\section{Introduction}

The importance of thiadiazoles was improved when the sulfa-drugs were invented [1]. These compounds are characterized by high biological activity and found application as antifungal and antimicrobial compounds as well as antitumer compounds [2] [3] [4]. The coupling of acetylene with thiadiazoles showed anti-choline esterase enzyme. They were also incorporated in the thermal moldable polymers [5]. Some derivatives are employed as dyes, ion exchange resins in which thiadiazoles represent a major part were efficiently applied in the removal of several cations with $100 \%$ efficiency in some instances [6]. The 1,3,4-thiadiazole derivatives were preferably used as additives for the extreme pressure greases because they are biodegradable and hence friendly for the environment [7]. The interest in thiadiazole derivatives is growing and many new compounds are continuously synthesized for antifungal purposes (Karaburun, et al. [8]). Mahmood et al., synthesized and evaluated the activity of some thiadiazole Schiff base derivatives as antibacterial agents [9]. Compounds belonging to the group of 5-substituted 4-(1,3,4-thiadiazol-2-yl) benzene-1,3-diols exhibited a broad spectrum of biological activity, including antibacterial, antifungal, and anticancer properties. Chudzik et al. [10], reported the activity of 4-(5-methyl-1,3,4-thiadiazole-2-yl) benzene-1,3-diol, against pathogenic fungi with the lowest toxicity to human cells. The thiadiazole ring exhibits several specific properties: it is a bioisostere of pyrimidine or benzene rings with prevalence in biologically active compounds; the sulfur atom increases lipophilicity and combined with the mesoionic character of thiadiazoles imparts good oral absorption and good cell permeability, resulting in good bioavailability. The 2-amino-1,3,4-thiadiazole derivatives exhibited antileishmanial activity [11]. Kaur and Sing [12] published a review on the Thiadiazole analogs as potential pharmacological agents. Thiadiazole derivatives are utilized therapeutically for various diseases thanks to their antiviral [13], anticonvulsant [14] anti-inflammatory [15], anticancer [16] activities. It was also reported that thiadiazole derivatives demonstrated antithyroid activities [17]. Thiadiazole derivatives and its metal compounds have antibacterial, antifungal, antitumoral, antiproliferative and antioxidant properties. The effects caused by thiadiazole ligand and its metal complexes upon the fatty acids and lipophilic vitamins in livers of rats were examined by Parlak et al. [18]. Many methods were employed for the determination of 1,3,4-thiadiazoles. High performance liquid chromatography, HPLC, was used in the analysis of rice for traces of thiadiazoles after extraction and photometric detection at $313 \mathrm{~nm}$. Hitachi Gel was used as the stationary phase for the separation and refractive index for the detection of these compounds in the thermal decomposition products of thiobenzamide [19]. Amplification reactions are divided into direct and indirect methods [20] [21]. The indirect ones found many applications in the determination of various organic compounds [22], where they first react with iodine and the resultant iodide is then involved in an amplification reaction. Recently, 
the method was applied for the determination of some thiosemicarbazone derivatives according to the equation:

$$
\begin{aligned}
& \mathrm{R}-\mathrm{CH}=\mathrm{N}-\mathrm{N}-\mathrm{C}-\mathrm{NH}_{2}+3 \mathrm{I}_{2}+6 \mathrm{H}_{2} \mathrm{O} \\
& \rightarrow \mathrm{R}-\mathrm{CH}_{3}+\mathrm{N}_{2}+\mathrm{NH}_{3}+\mathrm{HCOOH}+\mathrm{H}_{2} \mathrm{SO}_{4}+6 \mathrm{HI}
\end{aligned}
$$

The reactions are accompanied by a drop in the $\mathrm{pH}$ of the reaction mixture indicating the formation of the acids [23]. The present paper is concerned with the utilization of amplification reactions in the determination of some 1,3,4-thiadiazoles, compounds namely: 2-amino-5-mercapto-1,3,4-thiadiazole (I); 2,5-dimercapto1,3,4-thiadiaole (II) and 2,5-diamino-1,3,4-thiadiazole (III) and for 2,5-dihydrazino1,3,4-thiadiazole (IV), 5-(((5-nitrofuran-2-yl)methylene) amino)-1,3,4-thiadiazole2-thiol (V) and 5-mercapto-2[(3[5'-nitro-2-furyl]-prop-2-enylidene)amino]-1,3,4thiadiazole (VI). The evaluation was done by titration with thiosulfate standard solution and spectrophotometrically by measuring the absorbance of the blue starch-iodine complex.

\section{Experimental}

Apparatus: the spectral measurements were carried out on a U 2000 spectrophotometer supplied from Hitachi. The IR spectra were recorded on a Pye-Unicam SP 3-100 IR spectrophotometer.

Chemicals: All of the chemicals and reagents were of analytical grade. Distilled de-ionized water was used for rinsing and preparation of working solutions. The following thiadiazole compounds were prepared according to the published methods [24] [25] [26] [27] [28] and determined:

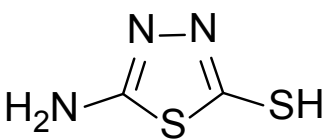

5-amino-1,3,4-thiadiazole-2-thiol (1)<smiles>Sc1nnc(S)s1</smiles>

1,3,4-thiadiazole-2,5-dithiol (2)<smiles>Nc1nnc(N)s1</smiles>

1,3,4-thiadiazole-2,5-diamine (3)

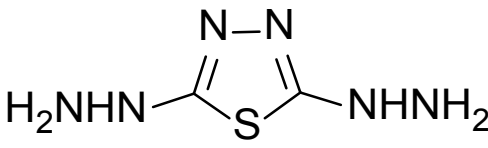

2,5-dihydrazinyl-1,3,4-thiadiazole (4) 
<smiles>O=[N+]([O-])c1ccc(C=Nc2nnc(S)s2)o1</smiles>

5-(((5-nitrofuran-2-yl) methylene)amino)-1,3,4-thiadiazole-2-thiol (5)<smiles>O=[N+]([O-])c1ccc(C=C=CNc2nnc(S)s2)o1</smiles>

5-mercapto-2-[(3[5'-nitro-2'-furyl]-prop-2'-enylidene)amino]-1,3,4-thiadiazole (5)

Working solutions:

1) Thiadiazole solutions: accurately about $0.1 \mathrm{~g}$ of each compound was dissolved in $6 \mathrm{~mL}$ of ethanol (99\%) and water was added up to a volume of $100-\mathrm{mL}$ in a calibrated flask.

2) Potassium iodate solution $0.01 \mathrm{~N}$; sodium thiosulfate $0.01 \mathrm{~N}$; potassium iodide $0.5 \%$; iodine $0.12 \%$ in chloroform and bromine water solution was prepared by gradually diluting $5-\mathrm{mL}$ of bromine with water up to a final volume of $250 \mathrm{~mL}$.

3) Buffers: a series of acetate buffer solutions were prepared according to the standard methods [19].

4) Interfering solutions: The interference solutions were prepared to be 10,000 $\mu \mathrm{g} \cdot \mathrm{mL}^{-1}$ in the appropriate solvents.

Procedure: $1.0 \mathrm{~mL}$ aliquot of thiadiazole solution was placed in a $100-\mathrm{mL}$ separating funnel and $10 \mathrm{mLs}$ of acetate buffer solution and $10 \mathrm{mLs}$ of iodine solution were added. After 5 mins of shaking, the water phase was separated from the upper organic phase. The water layer was washed twice with 10 -ml aliquots of chloroform to remove residual iodine. Bromine water was added to the aqueous phase and the mixture was shaken for 2 mins. Excess bromine was removed by adding $2 \mathrm{mLs}$ of formic acid. Finally $0.5 \mathrm{~g}$ of potassium iodide were added. The generated iodine was determined by titration with standard thiosulfate solution.

For spectral detection thiadiazole solution aliquot containing $50 \mu \mathrm{g}$ was found enough and the same procedure was followed with the exception of addition of KI where 2-mLs of $0.5 \% \mathrm{KI}$ solution followed by $1 \mathrm{ml}$ of starch indicator solution. The absorbance of the resultant solutions was then measured. The effects of various operating parameters on the response were studied to reach the optimum conditions of the analysis.

\section{Results and Discussion}

\section{Verification of the composition of thiadiazole compounds:}

The compounds were prepared according to the published methods and melting points, UV and IR spectra were recorded. The results are listed in Table 1. The assignment of the IR peaks is presented in Table 2. 
Table 1. Summary of the results verification of the composition of thiadiazole compounds.

\begin{tabular}{ccc}
\hline Compound & m.p. & $\lambda_{\max }, \mathrm{nm}$ \\
\hline 1 & $231-233$ & 370,307 \\
2 & $159-161$ & 373 \\
3 & $240-242$ & $372,311,263$ \\
4 & $251-253$ & 340,371 \\
5 & $206-208$ & 436 \\
6 & $204-206$ & 455 \\
\hline
\end{tabular}

Table 2. The assignment of the IR peaks.

\begin{tabular}{cccccccc}
\hline \multirow{2}{*}{ Compound } & \multicolumn{7}{c}{ IR Characteristic bands, $\mathrm{cm}^{-1}$} \\
\cline { 2 - 7 } & $v(\mathrm{C}-\mathrm{S})$ & $v(\mathrm{C}=\mathrm{N})$ & $v(\mathrm{~S}-\mathrm{H})$ & $v(\mathrm{~N}-\mathrm{H})$ & $v(\mathrm{C}-\mathrm{N})$ & $v(\mathrm{C}=\mathrm{C})$ & $v\left(\mathrm{NH}_{2}\right)$ \\
\hline 1 & 750 & 1600 & 2600 & 3250 & 1070 & & $3093-3350$ \\
2 & 750 & 1550 & 2550 & & & & \\
3 & 730 & 1610 & & 3300 & 1200 & 3300 \\
4 & 750 & 1640 & & 3300 & 1210 & & 3400 \\
5 & 730 & 1650 & 2580 & & & 1560 & \\
6 & 750 & 1650 & 2580 & & & 1610 & \\
\hline
\end{tabular}

\section{Effect of $\mathrm{pH}$ of the solution:}

The reactions were carried out in media of various $\mathrm{pH}$ values and the response was recorded. For compounds (I - III) the response is plotted in Figure 1. For compounds IV - VI, the results are shown in Figure 2. Numerically the: Effect of medium on the reaction ( $10 \mathrm{~mL}$ reagent) extent of $1.00 \mathrm{mg}$ of compounds (3) is given in Table 3. It is clear that the optimum $\mathrm{pH}$ value is dependent on the chemical composition. However, Compounds II, V and VI require more acidic conditions than the others to attain the highest reaction extents. This may be the effect of the thiol group.

Effect of Iodine amount:

After the optimization of the $\mathrm{pH}$ of the reaction mixture which allows the best reaction extent of the thiadiazole derivatives with iodine, the effect of Iodine solution volume was studied. Various volumes $(1-20 \mathrm{~mL})$ of the iodine dissolved in chloroform $(0.12 \%)$ solution were employed in the reaction. After reaction with thiadiazole, iodine is transferred into the aqueous layer for determination by titration. The best response could be obtained with 5 -mLs aliquots of the iodine solution. Thus, such amount was fixed for all experiments.

The reaction of thiadiazoles with iodine was allowed to proceed for various intervals of time and the response was recorded. For compounds I and II five minutes appeared enough to give the highest yield. On the other hand, compound III required only one min while two mins were required for compounds $\mathrm{V}$ and VI to complete reaction with iodine. This can be related to the acidity of the hydrogen atom of the functional groups especially the $\mathrm{NHNH}_{2}, \mathrm{NH}_{2}$ and $\mathrm{SH}$. 


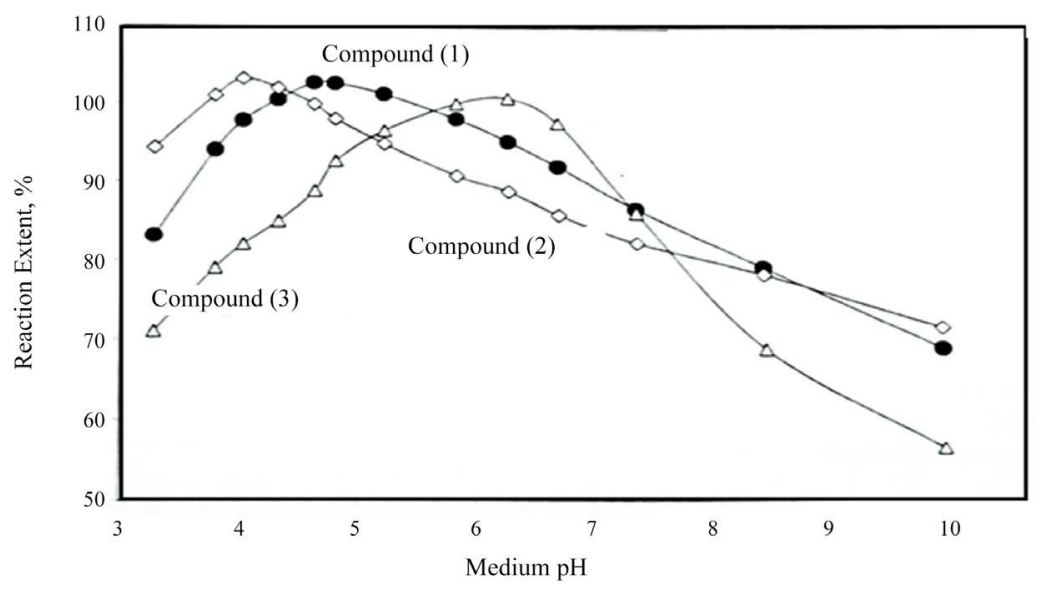

Figure 1. Effect of $\mathrm{pH}$ of the medium on the reaction of compounds $1 ; 2$; and 3.

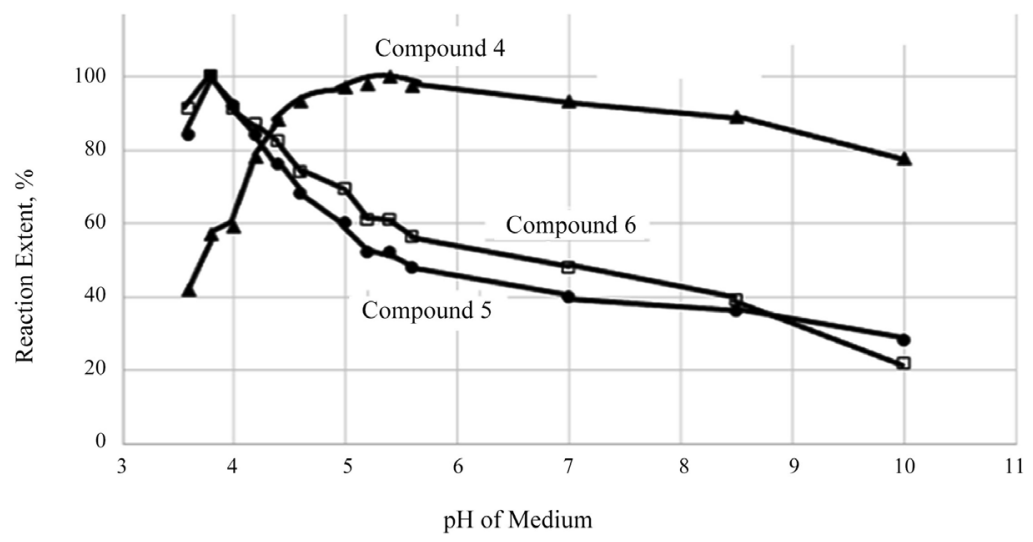

Figure 2. Effect of $\mathrm{pH}$ of the medium on the reaction of compounds 4, 5, and 6 .

Table 3. Effect of medium on the reaction ( $10 \mathrm{~mL}$ reagent) extent of $1.00 \mathrm{~g}$ of compounds (III).

\begin{tabular}{ccc}
\hline Reaction Medium & Volume of thiosulfate $(0.01 \mathrm{~N})$ solution, $\mathrm{mL}$. & Recovery, $\%$ \\
\hline $\mathrm{HCl}(0.1 \mathrm{M})$ & 5.4 & 54.0 \\
water & 6.4 & 64.0 \\
Acetate buffer $(\mathrm{pH}, 3.6)$ & 7.1 & 71.0 \\
Acetate buffer $(\mathrm{pH}, 3.8)$ & 7.9 & 79.0 \\
Acetate buffer $(\mathrm{pH}, 4.0)$ & 8.2 & 82.0 \\
Acetate buffer $(\mathrm{pH}, 4.2)$ & 8.4 & 84.0 \\
Acetate buffer $(\mathrm{pH}, 4.4)$ & 8.7 & 87.0 \\
Acetate buffer $(\mathrm{pH}, 4.6)$ & 9.1 & 91.0 \\
Acetate buffer $(\mathrm{pH}, 5.0)$ & 9.7 & 97.0 \\
Acetate buffer $(\mathrm{pH}, 5.2)$ & 10.0 & 100 \\
Acetate buffer $(\mathrm{pH}, 5.4)$ & 9.8 & 98.0 \\
Acetate buffer $(\mathrm{pH}, 5.6)$ & 9.6 & 96.0 \\
Acetate buffer $(\mathrm{pH}, 7.0)$ & 8.6 & 86.0 \\
Acetate buffer $(\mathrm{pH}, 8.5)$ & 6.9 & 69.0 \\
Acetate buffer $(\mathrm{pH}, 10.0)$ & 5.7 & 57.0 \\
\hline
\end{tabular}


The amount of bromine water necessary to oxidize the iodide produced by the first reaction was studied. It appeared that aliquots of 1 - $4 \mathrm{mLs}$ were adequate for the complete oxidation of iodide into iodate. Thus, $2 \mathrm{mLs}$ of saturated bromine water were added to each sample solution and fixed all over the work. The oxidation can be aided by shaking the reactants for not less than (3 - 5) mins. For all experiments three minutes reaction time was chosen. However, any excess bromine needs to be destroyed in order not to consume part of the thiosulfate solution later on. Table 4 shows the effect of formic (90\%) volume required for the destruction reaction. Below $1.0 \mathrm{mLs}$, the destruction is incomplete and the thiosulfate was consumed in excess. Thus, $2-\mathrm{mL}$ aliquot was fixed for such reaction.

The final step of the amplification process involves the reaction of the iodate ions, produced therein, with potassium iodide. Each iodate ion requires five iodide ions for this reaction. Potassium iodide, therefore, must be added in excess $(0.2-1.0 \mathrm{~g})$ to the reaction mixture. However, an amount of $0.5 \mathrm{~g}$ of solid potassium iodide was found enough to perform this job. The titration was carried out after various time intervals up to ten minutes. The results of compound (I) clearly showed that titration can be done immediately after the addition and mixing of potassium iodide crystals with the reaction mixture, where iodine is liberated.

Calculation of the number of iodine moles per mole of Thiadiazole derivatives:

One mg of compound (I) is equivalent to mLs of standard $0.01 \mathrm{~N}$ sodium thiosulfate ( $0.244 \mathrm{meq})$ and consequently to $0.244 \mathrm{meq}$ of iodine. The overall amplification factor, therefore, is $0.244 / 0.0075=12$. As mentioned above, iodate reacts with five iodide ions to give three iodine molecules, i.e. the iodate is amplified six times. The division of overall amplification on the iodate amplification gave (2). Therefore, each mole of compound (I) releases two iodide moles by reaction with iodine, i.e. one mole of iodine is required by one mole of compound (I). Similarly. It was found that:

one mole of iodine reacts with one mole of II;

one mole of iodine reacts with one mole of III;

three moles of iodine react with one mole of IV;

half a mole of iodine react with one mole of $\mathrm{V}$;

half a mole of iodine reacts with one mole of VI. Therefore:

$1.0 \mathrm{~mL}$ of $0.01 \mathrm{~N}$ thiosulfate solution $=0.108 \mathrm{mg}$ of compound $\mathrm{I}$

$1.0 \mathrm{~mL}$ of $0.01 \mathrm{~N}$ thiosulfate solution $=0.126 \mathrm{mg}$ of compound II

$1.0 \mathrm{~mL}$ of $0.01 \mathrm{~N}$ thiosulfate solution $=0.1 \mathrm{mg}$ of compound III

$1.0 \mathrm{~mL}$ of $0.01 \mathrm{~N}$ thiosulfate solution $=0.041 \mathrm{mg}$ of compound IV

$1.0 \mathrm{~mL}$ of $0.01 \mathrm{~N}$ thiosulfate solution $=0.4 \mathrm{mg}$ of compound $\mathrm{V}$

$1.0 \mathrm{~mL}$ of $0.01 \mathrm{~N}$ thiosulfate solution $=0.435 \mathrm{mg}$ of compound VI

Mechanism of Amplification Reaction:

On basis of experiments and calculations, the following mechanism may be proposed for the amplification reactions of thiadiazole derivatives: 
Table 4. The effect of formic (90\%) volume required for the destruction of excess bromine water on the reaction of $1.00 \mathrm{mg}$ of compound (I).

\begin{tabular}{|c|c|c|c|}
\hline Volume of formic acid (mL) & Volume of $\mathrm{S}_{2} \mathrm{O}_{3}^{2-}$ & $(0.01 \mathrm{M})$ solution $(\mathrm{mL})$ & Recovery (\%) \\
\hline 0.1 & & 11.5 & 125.0 \\
\hline 0.3 & & 10.9 & 118.4 \\
\hline 0.5 & & 10.6 & 115.2 \\
\hline 1.0 & & 9.2 & 100 \\
\hline 2.0 & & 9.2 & 100 \\
\hline 3.0 & & 9.2 & 100 \\
\hline
\end{tabular}

Compd. I $+\mathrm{I}_{2}+4 \mathrm{H}_{2} \mathrm{O} \rightarrow$ Thiadiazole $+2 \mathrm{HI}+\mathrm{H}_{2} \mathrm{SO}_{4}+\mathrm{NH}_{3}+\mathrm{H}_{2}$

Compd. II $+\mathrm{I}_{2}+4 \mathrm{H}_{2} \mathrm{O} \rightarrow$ Thiadiazole $+2 \mathrm{HI}+\mathrm{H}_{2} \mathrm{SO}_{4}+\mathrm{H}_{2} \mathrm{~S}+\mathrm{H}_{2}$

Compd. III $+\mathrm{I}_{2}+2 \mathrm{H}_{2} \mathrm{O} \rightarrow$ Thiadiazole $+2 \mathrm{HI}+\mathrm{NH}_{3}+\mathrm{NO}_{2}+\frac{1}{2} \mathrm{H}_{2}$

Compd. IV $+3 \mathrm{I}_{2}+4 \mathrm{H}_{2} \mathrm{O} \rightarrow$ Thiadiazole $+6 \mathrm{HI}+2 \mathrm{NH}_{3}+2 \mathrm{NO}_{2}$

Compd. V $+\frac{1}{2} \mathrm{I}_{2}+6 \mathrm{H}_{2} \mathrm{O}$

$\rightarrow$ Thiadiazole $+\mathrm{HI}+\mathrm{H}_{2} \mathrm{SO}_{4}+\mathrm{NO}_{2}+3 \mathrm{H}_{2}+\mathrm{O}_{2} \mathrm{~N}\left(\mathrm{C}_{4} \mathrm{H}_{20}\right) \mathrm{CH}_{3}$

Compound $\mathrm{VI}+\frac{1}{2} \mathrm{I}_{2}+6 \mathrm{H}_{2} \mathrm{O}$

$\rightarrow$ Thiadiazole $+\mathrm{HI}+\mathrm{H}_{2} \mathrm{SO}_{4}+\mathrm{NO}_{2}+3 \mathrm{H}_{2}+\mathrm{O}_{2} \mathrm{~N}\left(\mathrm{C}_{4} \mathrm{H}_{20}\right) \mathrm{CH}=\mathrm{CH}-\mathrm{CH}_{3}$

The increase of the acidity of the reaction media supports these mechanisms reaching $\mathrm{pH}$ values of $(4-5)$ and the occurrence of gas evolution. Further the smell of ammonia was noticed in the case of reaction 3, 5, and 6 and the hydrogen sulfide in the case of reaction (4). The hydroiodic acid or the iodide ions produced undergo the following amplification reactions:

$$
\begin{gathered}
\mathrm{I}^{-}+\text {Bromine/water } \rightarrow \mathrm{IO}_{3}^{-} \\
\mathrm{IO}_{3}^{-}+5 \mathrm{I}^{-}+6 \mathrm{H}^{+} \rightarrow 3 \mathrm{I}_{2}+3 \mathrm{H}_{2} \mathrm{O} \\
\mathrm{I}_{2}+2 \mathrm{~S}_{2} \mathrm{O}_{3}^{2-} \rightarrow \mathrm{S}_{4} \mathrm{O}_{6}^{2-}+2 \mathrm{I}^{-}
\end{gathered}
$$

Each iodide ion, therefore, produces three iodine molecules or six iodine atoms and the amplification factor will be (12) for compounds I - III, (36) for compound IV and only (6) for compounds V and VI.

\section{Precision and Accuracy:}

Under the optimum conditions, the precision of the method was checked by evaluating the relative standard deviation at three different concentrations of each thiadiazole derivative. The results are listed in Table 5. The low precision is related to the presence of sources of errors mainly due to the measurement of the volume of thiosulfate solution.

Interference:

The effects of some organic and ionic compounds on the reaction of thiadiazoles with iodine were studied. The percentage changes in the response of $1.0 \mathrm{mg}$ 
of compound I in the presence of the interfering compound at 1,5,10,50,100, 250 and 500 times of its concentration are shown in Table 6. It appears that, compounds having similar functional groups cause interference effects. The use of thiadiazole in pharmaceutical preparations [23] and as additives in special greases [6], were the reason of studying the effects of the other chemicals shown in Table 6. Glucose and lithium 12-hydroxy stearate have only minor interferences due to the hydroxyl group of the weak acidity. However, neither of sodium chloride, lithium stearate, or base oil showed any interference on the analytical performance. The same conclusion holds for other thiadiazole derivatives.

\section{Spectrophotometric-Amplification Reactions:}

Using the same experimental optimum conditions the detection of the blue iodine-starch complex could be accomplished by measuring the absorbance at $605 \mathrm{~nm}$ [22]. Before the detection step, potassium iodide was used as a $0.5 \%$ solution and several amounts were examined $(0.5-4.0 \mathrm{~mL})$. An aliquot of $2.0 \mathrm{~mL}$ was found adequate for this purpose. The volume of the starch indicator solution was not critical and $1-5 \mathrm{mLs}$ gave no differences in the response at $605 \mathrm{~nm}$. However, a volume of $1.0 \mathrm{~mL}$ was fixed for all measurements.

The color of the solution develops immediately and no absorbance can be measured directly after the addition of the starch solution. The measurement of the absorbance after various intervals of time indicated that 30 minutes must not be exceeded and color may begin to diminish gradually. Thus, all absorbance measurements were done within the first $20 \mathrm{~min}$ after adding starch solution and dilution to the appropriate volume in the volumetric flask. Calibration graphs for the six compounds were constructed. The analytical parameters are calculated and listed in Table 7. The accuracy and precision of the method were tested at three levels of concentration and the results are given in Table 8. It is clear that the recovery values were acceptable and ranges between $95 \%$ to $102 \%$. The interference effects were similar to those noticed above for the titrimetric method.

Table 5. Relative standard deviation, RSD, recovery and relative error for three levels of concentrations of thiadiazole derivatives*.

\begin{tabular}{ccccc}
\hline Compound & Amount taken (mg) & Relative error \% & RSD (\%) & Recovery (\%) \\
\hline \multirow{2}{*}{ I } & 0.05 & -4.8 & 2.7 & 95.2 \\
& 0.5 & -2.8 & 0.8 & 97.2 \\
& 2.0 & 0.8 & 0.2 & 100.8 \\
II & 0.05 & -3.6 & 5.1 & 96.4 \\
& 0.5 & -0.4 & 3.2 & 99.6 \\
& 2.0 & +0.5 & 0.2 & 100.5 \\
III & 0.05 & -1.2 & 4.1 & 98.8 \\
& 0.5 & -0.4 & 3.2 & 99.6 \\
& 2.0 & +0.1 & 0.8 & 100.1 \\
\hline
\end{tabular}




\section{Continued}

\begin{tabular}{ccccc}
\hline & 0.05 & -2.0 & 6.1 & 98.0 \\
IV & 0.5 & -0.8 & 1.1 & 99.2 \\
& 2.0 & +0.3 & 0.9 & 100.3 \\
$\mathrm{~V}$ & 0.05 & -5.6 & 2.3 & 94.4 \\
& 0.5 & -3.3 & 1.8 & 96.6 \\
& 2.0 & +1.4 & 0.5 & 101.4 \\
$\mathrm{VI}$ & 0.05 & -5.6 & 6.1 & 94.4 \\
& 0.5 & -0.9 & 1.2 & 99.1 \\
\hline
\end{tabular}

*Results are the mean of five readings from which the blank result is subtracted.

Table 6. Percentage interferences of various chemicals with the analysis of $1.00 \mathrm{mg}$ of compound I using the optimum conditions.

\begin{tabular}{ccccccc}
\hline & \multicolumn{7}{c}{ Interference \% } \\
\cline { 2 - 7 } Interfering Compounds & \multicolumn{7}{c}{ Interferent concentration (mg) } \\
\cline { 2 - 7 } & 5 & 10 & 50 & 100 & 250 & 500 \\
\hline 2-mercaptothiadiazole & +86.9 & +143.5 & SI & SI & SI & SI \\
2-mercaptoimidazole & +78.2 & +93.4 & SI & SI & SI & SI \\
3-amino-1,2,4 triazole & +67.3 & +123.9 & SI & SI & SI & SI \\
2-mercaptobenzoic acid & +79.3 & +136.9 & SI & SI & SI & SI \\
Sodium chloride & - & - & - & - & - & - \\
Glucose & +3.2 & +4.3 & +7.6 & +8.6 & +9.7 & +13.0 \\
Lithium 12 hydroxystearate & +1.6 & +2.1 & +3.2 & +5.4 & +10.8 & +17.3 \\
Lithium stearate & - & - & - & - & - & - \\
Base oil & - & - & - & - & - & - \\
Grease & +1.0 & +1.6 & +2.1 & +3.2 & +5.4 & +8.6 \\
\hline
\end{tabular}

SI $=$ Serious interference.

Table 7. The analytical parameters of the spectral determination of thiadiazoles.

\begin{tabular}{cccccc}
\hline compound & $\begin{array}{c}\text { linearity limit } \\
(\mathrm{ppm})\end{array}$ & $\begin{array}{c}\text { Molar absorptivity } \\
\left(\mathrm{L} \cdot \mathrm{mol}^{-} \cdot \mathrm{cm}^{-}\right.\end{array}$ & $\begin{array}{c}\text { Sandell's } \\
\text { Index } \mathrm{g} \cdot \mathrm{cm}^{2-}\end{array}$ & $\begin{array}{c}\text { Sensitivity } \\
(\mathrm{ppm})\end{array}$ & $\begin{array}{c}\text { Detection } \\
\text { limit }(\mathrm{ppm})\end{array}$ \\
\hline 1 & $0.25-4.0$ & $3.22 \times 10^{4}$ & 0.0041 & 0.0129 & 0.066 \\
2 & $0.25-4.0$ & $4.24 \times 10^{4}$ & 0.0035 & 0.0106 & 0.057 \\
3 & $0.25-6.0$ & $2.43 \times 10^{4}$ & 0.0048 & 0.0137 & 0.077 \\
4 & $0.25-6.0$ & $4.82 \times 10^{4}$ & 0.0030 & 0.0122 & 0.049 \\
5 & $0.25-5.0$ & $2.64 \times 10^{4}$ & 0.0097 & 0.0523 & 0.156 \\
6 & $0.25-5.5$ & $3.19 \times 10^{4}$ & 0.0088 & 0.0215 & 0.143 \\
\hline
\end{tabular}


Table 8. Accuracy and precision of the spectral determination of thiadiazoles.

\begin{tabular}{|c|c|c|c|c|}
\hline Compound & Concentration (ppm) & Relative Error (\%) & $\begin{array}{l}\text { Relative Standard } \\
\text { Deviation (\%) }\end{array}$ & Recovery (\%) \\
\hline & 1.25 & -3.4 & 1.2 & 96.6 \\
\hline \multirow[t]{3}{*}{1} & 2.5 & -2.0 & $0 / 6$ & 98.0 \\
\hline & 3.5 & +1.4 & 0.3 & 101.4 \\
\hline & 1.25 & -4.0 & 1.3 & 96.0 \\
\hline \multirow[t]{3}{*}{2} & 2.25 & -2.7 & 0.5 & 97.3 \\
\hline & 3.25 & $\_1.4$ & 0.3 & 101.4 \\
\hline & 1.5 & -4.7 & 1.5 & 95.3 \\
\hline \multirow[t]{3}{*}{3} & 3.0 & -1.6 & 0.3 & 98.4 \\
\hline & 5.0 & +1.1 & 0.1 & 101.1 \\
\hline & 1.5 & -4.4 & 1.9 & 96.0 \\
\hline \multirow[t]{3}{*}{4} & 3.0 & -1.7 & 0.4 & 98.3 \\
\hline & 5.0 & +2.0 & 0.3 & 102.0 \\
\hline & 2.5 & -6.0 & 1.1 & 95.0 \\
\hline \multirow[t]{3}{*}{5} & 3.5 & -1.5 & 0.8 & 98.5 \\
\hline & 4.5 & +1.1 & 0.3 & 101.1 \\
\hline & 1.5 & -4.4 & 2.0 & 96.0 \\
\hline \multirow[t]{2}{*}{6} & 3.5 & -1.2 & 0.5 & 98.8 \\
\hline & 5.0 & +1.0 & 0.2 & 101.0 \\
\hline
\end{tabular}

\section{Conclusion}

Thiadiazole derivative can be analyzed efficiently by amplification reactions with iodine with appreciable accuracy and amplification factors ranging from 6 to 36 . Spectrophotometric as well as titrimetric detection can be used to evaluate the response of the method. The method is characterized by relatively high sensitivity and precision with acceptable recovery values (94.4\% - 102.0\%) at several levels of concentration. Compounds with functional groups similar to those of thiadiazoles may interfere in the analysis.

\section{Conflicts of Interest}

The authors declare no conflicts of interest regarding the publication of this paper.

\section{References}

[1] Emilson, H. (1989) Synthesis of 3,4,5-Triamino-4H-1,2,4-triazole (Guanazine) and Its 4-Arylideneamino Derivatives. Journal of Heterocyclic Chemistry, 26, 1077-1081. https://doi.org/10.1002/jhet.5570260431

[2] Eldeen, Z.M., Al-Jawad, F. and Eldin, S. (1982) Synthesis and Biological Evaluation of 2-(4-Tert-amino2-butynyl)thio-5-aryl-1,3,4-thiadiazoles. European Journal of 
Medicinal Chemistry, 17, 479-481.

[3] Raj, V., Rai, A., Singh, M., Kumar, R., Kumar, A., Kumar, V. and Sharma, S.K. (2015) Recent Update on 1,3,4-Thiadiazole Derivatives: As Anticonvulsant Agents, American Research Journal of Pharmacy, 1, 34-61.

[4] Alam, F. (2018) Antimicrobial Activity of 1,3,4-Thiadiazole Derivatives: A Recent Review. Journal of Applied Pharmaceutical Research, 6, 10-19.

[5] Wilkins, D.J. (2008) Five-Membered Rings: Triazoles, Oxadiazoles, Thiadiazoles and Their Fused Carbocyclic Derivatives. In Comprehensive Heterocyclic Chemistry III.

[6] Hu, Y., Li, C.-Y., Wang, X.-M., Yang, Y.-H. and Zhu, H.-L. (2014) 1,3,4-Thiadiazole: Synthesis, Reactions, and Applications in Medicinal, Agricultural, and Materials Chemistry, Chemical Reviews, 114, 5572-5610. https://doi.org/10.1021/cr400131u

[7] Kumar Jain, A., Sharma, S., Vaidya, A., Ravichandran, V. and Agrawal, R.K. (2013) 1,3,4-Thiadiazole and Its Derivatives: A Review on Recent Progress in Biological Activities. Chemical Biology Drug Design, 81, 557-576.

https://doi.org/10.1111/cbdd.12125

[8] Karaburun, A.C., Çevik, U.A., Osmaniye, D., Sağlık, B.N., Çavuşoğlu, B.K., et al. (2018) Synthesis and Evaluation of New 1,3,4-Thiadiazole Derivatives as Potent Antifungal Agents. Molecules, 23, 3129. https://doi.org/10.3390/molecules23123129

[9] Mahmood, A.E., Rashad, A.A., Daham, S.N. and Akram, E. (2019) Synthesis and Evaluation the Activity of 1,3,4-Thiadiazole Derivatives as Antibacterial Agent against Common Pathogenic Bacteria. Al-Nahrain Journal of Science, 22, 25-32. https://doi.org/10.22401/ANJS.22.1.04

[10] Chudzik, B., Bonio, K., Dabrowski, W., Pietrzak, D., Niewiadomy, A.A., Olender, A., et al. (2019) Antifungal Effects of a 1,3,4-Thiadiazole Derivative Determined by Cytochemical and Vibrational Spectroscopic Studies. PLOS ONE, 14, e0222775. https://doi.org/10.1371/journal.pone.0222775

[11] Serban, G. (2019) Future Prospects in the Treatment of Parasitic Diseases: 2-Amino1,3,4-Thiadiazoles in Leishmaniasis. Molecules, 24, 1557. https://doi.org/10.3390/molecules24081557

[12] Kaur, G. and Singh, R. (2014) Thiadiazole Analogs as Potential Pharmacological Agents: A Brief Review. International Journal of Pharmacy and Pharmaceutical Sciences, 6, 35-46.

[13] Kritsanida, M., Mouroutsou, A., Marakos, P., Pouli, N., Papakonstantinou-Garoufalias, S., et al. (2002) Antiviral Synthesis and Antiviral Activity Evaluation of Some New 6-Substituted 3-(1-Adamantyl)-1,2,4-triazolo[3,4-b][1,3,4]thiadiazoles. II Farmaco, 57, 253-257. https://doi.org/10.1016/S0014-827X(01)01189-2

[14] De Lima, J.G., Perrissin, M., Chantegrel, J., Luu-Duc, C., Rousseau, A. and Narcisse, G. (1994) Synthesis and Pharmacological Evaluation of Some 3-Phenacyl-5-benzylidene-thiazylidine-2 Thiazolidine-2,4-diones. Arzneimittelforschung, 44, 831-834.

[15] Kadi, A.A., El-Brollosy, N.R., Al-Deeb, O.A., Habib, E.E., Ibrahim, T.M. and El-Emam, A.A. (2007) Synthesis, Antimicrobial, and Anti-Inflammatory Activities of Novel 2-(1-Adamantyl)-5-substituted-1,3,4-oxadiazoles and 2-(1-Adamantylamino)-5substituted-1,3,4-thiadiazoles. European Journal of Medicinal Chemistry, 42, 235-242. https://doi.org/10.1016/j.ejmech.2006.10.003

[16] Çevik, U.A., Osmaniye, D., Levent, S., Saglik, B.N., Çavusoglu, B.K., Özkay, Y. and Kaplancikl, Z.A. (2020) Synthesis and Characterization of a New Series of Thiadiazole Derivatives as Potential Anticancer Agents. Heterocyclic Communications, 26, 6-13. https://doi.org/10.1515/hc-2020-0002 
[17] Jackson, T., Woo, L.W., Trusselle, M.N., Chander, S.K., Purohit, A., Reed, M.J. and Potter, B.V. (2007) Dual Aromatase-Sulfatase Inhibitors Based on the Anastrozole Template: Synthesis, In Vitro SAR, Molecular Modelling and In Vivo Activity. Organic \& Biomolecular Chemistry, 5, 2940-2952. https://doi.org/10.1039/b707768h

[18] Parlak, A.E., Karagozoglu, Y., Alayunt, N.Ö., Turkoglu, S., Karatepe, M. and Koparir, M. (2018) The Determination of the Effect of Some 1,3,4 Thiadiazole Derivatives on Biochemical Content (Fatty Acids, Sterols, Lipophilic Vitamins) in Rat Liver. Cellular and Molecular Biology (Noisy le Grand), 6, 35-39. https://doi.org/10.14715/cmb/2018.64.3.6

[19] Belcher, R. (1968) Amplification Reactions. Talanta, 15, 357-366. https://doi.org/10.1016/0039-9140(68)80243-7

[20] Al-Abachi, M.Q., Al-Hafidh, M.S. and Rahim, S.A. (1988) Titrimetric Determination of Microgram Amounts of Silver by Thiocyanate Amplification after Precipitation as Silver Hexathiocyanatochromate(III). Microchemical Journal, 37, 110-113. https://doi.org/10.1016/0026-265X(88)90175-0

[21] Amin, D. and Sulaiman, S.T. (1984) Titrimetric, Spectrophotometric and Polarographic Determination of Resorcinol, Catechol and Phloroglucinol. Analyst, 109, 739. https://doi.org/10.1039/an9840900739

[22] Al-Bayati, R.I., Barbooti, M.M. and Al-Hemiary, N.A. (2002) Determination of Some Thiosemicarbazone Derivatives by Amplification Reaction Methods. Iraqi Journal of Chemistry, 28, 149-156.

[23] Al-Hemiary, N.A. (2001) Determination of Thiosemicarbazone Derivatives by Amplification Reaction and Spectrophotometric Methods. M.Sc. Thesis, Al-Mustansiriyah University, Baghdad.

[24] Ameen, H.A. and Qasir, A.J. (2012) Synthesis and Preliminary Antimicrobial Study of 2-Amino-5-mercapto-1,3,4-thiadiazole Derivatives. Iraqi Journal of Pharmaceutical Sciences, 21, 98-104.

[25] Salimon, J., Salih, N., Yousif, E. and Ibraheem, H. (2010) Synthesis, Characterization and Biological Activity of Schiff Bases of 2,5-Dimercapto-1,3,4-thiadiazole. Australian Journal of Basic and Applied Sciences, 4, 2016-2021.

[26] Adebayo, M. (2011) Synthesis and Biological Activities on Metal Complexes of 2,5-Diamino-1,3,4-thiadiazole Derived from Semicarbazide Hydrochloride. Molecules, 16, 5862. https://doi.org/10.3390/molecules16075861

[27] Usova, E.B., Krapivin, G.D. and Kul'nevich, V.G. (1985) Synthesis and Properties of 5-(5-Nitro-2-furyl)thiazoline. Chemistry of Heterocyclic Compounds, 21, 1094-1097. https://doi.org/10.1007/BF00515245

[28] Hu, Y., Li, C.-Y., Wang, X.-M., Yang, Y.-H. and Zhu, H.-L. (2014) 1,3,4-Thiadiazole: Synthesis, Reactions, and Applications in Medicinal, Agricultural, and Materials Chemistry. Chemical Reviews, 114, 5572-5610. https://doi.org/10.1021/cr400131u 